\title{
ADSORPTION OF XYLENE ISOMERS IN METAL ORGANIC FRAMEWORK UiO-66 BY MOLECULAR SIMULATIONS
}

\author{
M. A. GRANATO, V. D. MARTINS, A. F. P. FERREIRA and A. E. RODRIGUES \\ LSRE Laboratory of Separation and Reaction Engineering - Associate Laboratory \\ LSRE/LCM. Faculdade de Engenharia, Universidade do Porto. Rua Dr. Roberto Frias, \\ 4200465 Porto, Portugal. \\ E-mail: mgranato@fe.up.pt
}

\begin{abstract}
This work presents results of molecular simulations on adsorption of the four xylene isomers (o-, $m$-, $p$-xylene and ethylbenzene) in the porous zirconium terephthalate UiO-66. Grand-canonical Monte Carlo simulations (GCMC) are compared to multi-component adsorption equilibrium data obtained by breakthrough experiments. Additionally, the adsorption behavior of each isomer in order to better understand the multicomponent adsorption was evaluated. The simulations confirm that the experimentally observed ortho-selectivity is preferential in relation to the other isomers. Access to the small cages seems to be favored for $o$-xylene due to its more compact structure that provides more advantages in terms of rotation degrees of freedom. Furthermore, it was found that there is a competition between the other three isomers for adsorption in the UiO-66.
\end{abstract}

\section{INTRODUCTION}

The recent synthesis of a new family of zirconium-based Metal Organic Frameworks (MOFs) with high surface area and exceptional stability opened a wide range of possibilities on separation applications. The $\mathrm{UiO} 66$ is based on a $\mathrm{ZrO}_{6}(\mathrm{OH})_{2}$ octahedron, and 1,4 benzene dicarboxylate (BDC) linkers. Its cubic 3D-pore structure consists of an array of octahedral cavities of diameter $1.1 \mathrm{~nm}$, and tetrahedral cavities of diameter $0.8 \mathrm{~nm}$ (Cavka et al., 2008). Repetitive hydration/dehydration tests have revealed that the dehydroxylated and hydroxylated versions of $\mathrm{UiO} 66$ are fully reversible.

However, studies on application of UiO 66 for separation of mixtures are still incipient. The first experimental study conducted for hexane and xylene isomers mixtures shows that the adsorption order of structural isomers in UiO 66 is opposite to the one observed in conventional adsorbents (Bárcia et al., 2011). This reverse shape selectivity was also observed for the xylene isomers adsorption in liquid phase, using n-heptane as eluent (Moreira et al., 2012).

The objective of the present work is to evaluate the behavior of single and multicomponent adsorption in UiO-66 by using four different molecular models of the xylene isomers, which are described as follows.

\section{METHODOLOGY}

The Monte Carlo technique in the grand-canonical $(\mu V T)$ ensemble has been extensively applied for calculations of adsorption properties, such as isotherms and 
heats of sorption. Detailed explanation of this simulation technique can be found elsewhere (Frenkel and Smit, 2002). The UiO-66 framework was considered rigid, and periodic boundary conditions were applied in all directions. The model was built from the X-ray diffraction data, taken from the Cambridge Crystallographic Data Centre (CCDC) under code 733458 (Cavka et al., 2008). This structure represents the dehydroxylated form of UiO-66, obtained after the activation procedure. The potential parameters for the non-metallic atoms were taken from the DREIDING force field. The Zirconium parameters were taken from the Universal force field since they are not available in the DREIDING force field. . A graphical representation of the UiO-66 framework is shown in Figure 1.

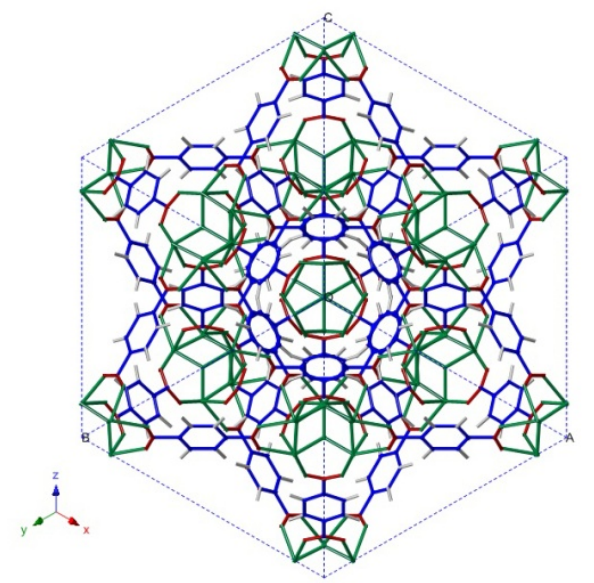

Figure 1 - Graphical representation of the UiO-66 unit cell.

The adsorbate molecules were simulated using four different approaches. The first two are well known from the literature:

Model 1 - The TraPPE model (Wick et al., 2000). In this model, the aromatic pseudo-atoms are treated as a single interaction center as well as the $\mathrm{CH}_{3} \mathrm{sp}^{3}$ and the $\mathrm{CH}_{2} \mathrm{sp}^{3}$ aliphatic pseudo-atoms.

Model 2 - The Optimized Potentials for Liquid Simulations - OPLS (Jorgensen et al., 1993) that is an all-atom model used for the substituted benzenes except the $\mathrm{CH}_{3} \mathrm{sp}^{3}$ aliphatic groups which are treated as united atoms centered on the carbon.

The other two models take the effect of the quadrupolar interactions of the aromatic ring into account by inserting three partial charges to the arenes and re-fitting their Lennard-Jones (LJ) parameters:

Model 3 - Extension of the TraPPE force field (Wick et al., 2002). This new representation of the arenes contains a positive partial charge $\left(\mathrm{q}_{\text {center }}=+2.42 \mathrm{e}\right)$, placed at the center of the ring, and two negative partial charges representing the $\pi$ electron clouds $\left(\mathrm{q}_{p i}=-1.21 \mathrm{e}\right)$, placed at a distance of $0.785 \AA$ from the ring center and on a line perpendicular to the arene plane.

Model 4 - Charged AUA model introduced by Nieto-Draghi et al. (2007). This model describes the electrostatic interactions inside the $\pi$ cloud of electrons by a positive partial charge $\left(\mathrm{q}_{\text {center }}=+8.13 \mathrm{e}\right)$, and two negative partial charges $\left(\mathrm{q}_{p i}=-4.065\right.$ e), at $0.4 \AA$ above and below the ring center. Zhai et al. (2012) used this model to 
investigate the diffusion of ortho- , meta- , and para-xylene in a FAU zeolite at 300$900 \mathrm{~K}$ by molecular dynamics simulations.

The TraPPE-UA force field considers all pseudo-atoms as neutrals, so partial charges are not needed. The OPLS-AA model for benzene makes use of partial charges at the carbon and hydrogen sites (Jorgensen et al., 1993). The Ewald summation technique is employed to calculate the long-range coulombic interactions in all cases where charges have been assigned (Models 2, 3, and 4).

The Lorentz-Berthelot mixing rules were employed to calculate the LJ cross interactions. The intermolecular potentials were truncated at $13 \AA$ for adsorption simulations. The simulation box consists of a $2 \times 2 \times 2$ supercell, which corresponds 8 unit cells of space group Fm-3m with lattice parameters $\mathrm{a}=20.743 \AA$, b $=20.743 \AA$, and c = $20.743 \AA$. Periodic boundary conditions were applied in all directions. Each simulation required $7.0 \times 10^{7}$ steps for equilibration followed by $7.0 \times 10^{7}$ steps for production.

\section{RESULTS AND DISCUSSION}

\subsection{Methane and $\mathrm{CO}_{2}$ Adsorption in UiO 66}

In order to validate the framework model and its potential parameters, we performed molecular simulations of $\mathrm{CH}_{4}$ and $\mathrm{CO}_{2}$ adsorption in UiO-66. The purpose is to evaluate the framework parameters by simulating adsorption properties of a neutral species $\left(\mathrm{CH}_{4}\right)$, and a charged species $\left(\mathrm{CO}_{2}\right)$.

Our results show a very good agreement with methane experimental data from Abid et al. (2012), who investigated the synthesis of UiO-66 with addition of ammonium hydroxide, and the effects of the additive on the structure and adsorption behavior in $\mathrm{CH}_{4}$ and $\mathrm{CO}_{2}$ adsorption compared with UiO-66 without functionalization. For $\mathrm{CO}_{2}$, our results are compared with simulations performed in a dehydroxylatedUiO-66 at $303 \mathrm{~K}$ (Wiersum et al., 2011).

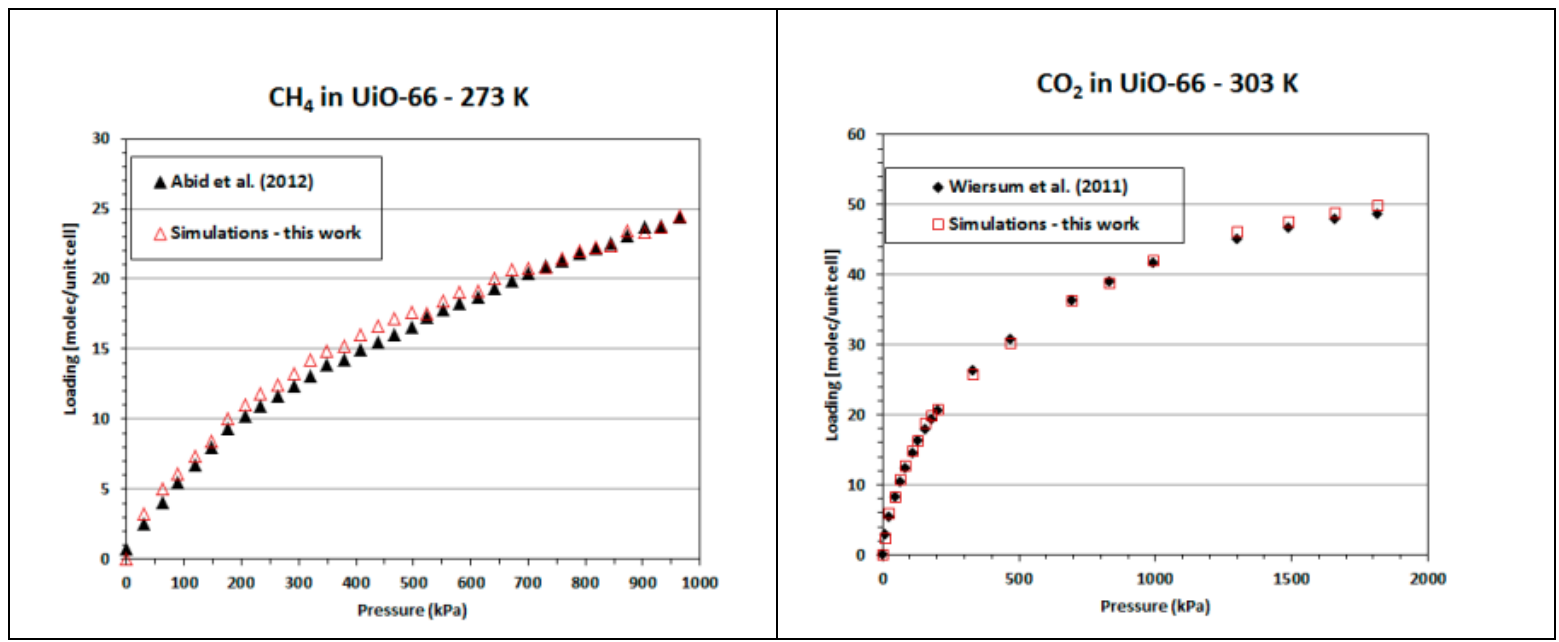

Figure 2 - Methane and $\mathrm{CO}_{2}$ adsorption isotherms in UiO-66.

The Lennard-Jones parameters for methane are the same in the OPLS (Jorgensen et al., 1986), and TraPPE (Martin and Siepmann, 1998) force fields. Figure 2 illustrates the simulated and experimental isotherms of methane, at $273 \mathrm{~K}$. Figure 3 shows $\mathrm{CO}_{2}$ 
simulation data. The good agreement between simulations and experiments allows us to apply the UiO-66 framework model to investigate the adsorption properties of xylene isomers, as described below.

\subsection{Molecular Simulation of Xylene Isomers Adsorption in UiO 66}

Single component equilibrium adsorption: It is necessary to evaluate the adsorption behavior of each isomer in order to better understand the multicomponent adsorption. The stacking of the xylene molecules within the MIL 47 and MIL 53 structures has been reported by Finsy et al. (2008, 2009), and Alaerts et al. (2007, 2008a, 2008b). This stacking is due to the interaction of the aromatic ring of the adsorbate molecules with the aromatic ring of the organic linker, so called $\pi-\pi$ stacking. Their selective behavior is due to different mechanisms. Finsy and co-workers reported that the selectivity in MIL-47 is due to packing in the channels. On the other hand, the selectivity in MIL-53 is due to differences in the adsorption enthalpy of the different isomers. (Maes et al., 2010). It is likely that a similar $\pi-\pi$ stacking behavior will take place also for UiO-66 type structures. Figure 4 shows the adsorption equilibrium isotherms, of the xylene isomers on UiO-66, at $398 \mathrm{~K}$, obtained by molecular simulations. It can be observed that UiO-66 is ortho-selective. Additionally, it also presents selectivity between meta-xylene and para-xylene, in a reverse order to their size/dimensions (reverse shape selectivity).

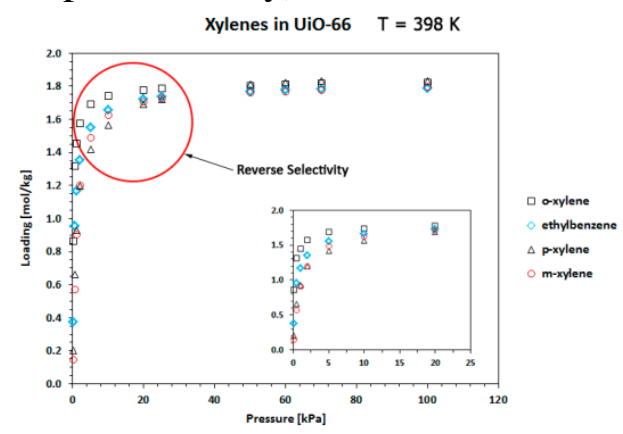

Figure 4 - Single component adsorption isotherms for the xylene isomers on UiO-66.

Isosteric heats of adsorption were obtained by GCMC simulations, from the combined energy/particle fluctuations (Karavias and Myers, 1991). Our results are shown in Table 4, and compared with results obtained from the literature (Chang and Yan, 2012). The results are in good agreement with each other. Figures 5a) and 5b) are a graphical representation of the data presented in Table 4. From Figure 5b) it can be observed that at low loadings the heats of adsorption are similar for the adsorption of the four components on UiO-66. Therefore, one can conclude that the main interaction between the adsorbate molecules and the structure is the $\pi-\pi$ stacking, maybe with weak contributions from the interactions of the methyl groups with framework. 
Table 4 - Heats of adsorption of the xylene isomers in UiO-66.

\begin{tabular}{|c|c|c|c|l|l|c|c|}
\hline \multicolumn{2}{|c|}{ ethylbenzene } & \multicolumn{2}{c|}{ o-xylene } & \multicolumn{2}{c|}{ p-xylene } & \multicolumn{2}{c|}{ m-xylene } \\
\hline molec/uc & heat & molec/uc & heat & molec/uc & heat & molec/uc & heat \\
\hline $0.00^{(a)}$ & $63.1^{(a)}$ & $0.00^{(a)}$ & $72.6^{(a)}$ & $0.00^{(a)}$ & $59.5^{(a)}$ & $0.00^{(a)}$ & $61.9^{(a)}$ \\
\hline 0.03 & 68.6 & 0.36 & 70.4 & 0.04 & 64.6 & 0.03 & 68.6 \\
\hline 0.30 & 68.0 & 2.80 & 62.4 & 0.15 & 63.8 & 0.31 & 67.1 \\
\hline 2.51 & 58.3 & 5.61 & 58.2 & 1.40 & 56.8 & 2.55 & 54.1 \\
\hline 8.74 & 44.7 & 7.98 & 54.6 & 8.91 & 42.3 & 8.72 & 33.3 \\
\hline
\end{tabular}

${ }^{a)}$ Experimental values from Chang and Yan (2012).
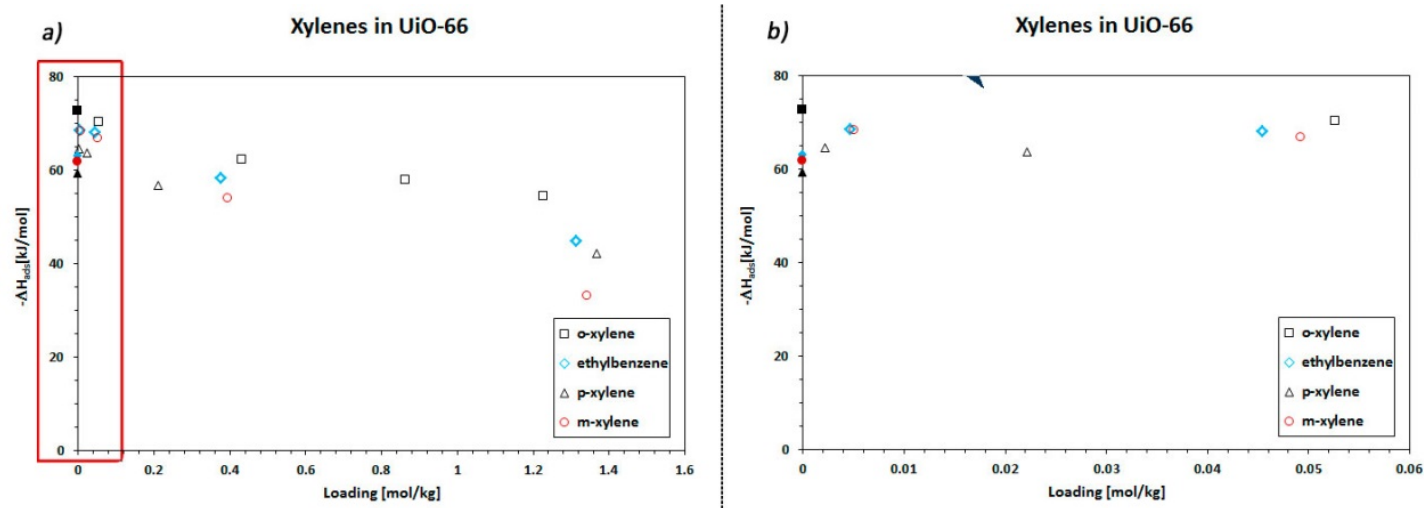

Figure 5 - Heats of adsorption versus loading, of the xylene isomers on UiO-66. Open symbols $=$ simulations (this work); closed symbols $=$ experimental (Chang and Yan, 2012). Zoomed area - red rectangle at left - (a) is shown at right (b).

Multicomponent equilibrium adsorption: Multicomponent adsorption of xylene isomers in UiO-66 was experimentally studied by means of quaternary breakthrough curves of an equimolar mixture at a total pressure of 1 and $10 \mathrm{kPa}$, and temperatures of 398 and 423 K (Bárcia et al., 2011). The experimental results demonstrate the higher retention of ortho-xylene over the other isomers. The least adsorbed is the para-xylene, while it has been also observed that meta-xylene, and ethylbenzene are not well distinguished. A comparison between experimental data and our simulations, at $398 \mathrm{~K}$ is shown in Table 5.

Although the selectivity towards ortho-xylene is higher in our simulations than the one observed experimentally, the preferential order of adsorption is well predicted by our simulations. The difference between experimental and simulated adsorbed amounts can be due to the UiO-66 framework flexibility due to the rotation/flip of the aromatic ring within the structure (Morris et al., 2011), leading to lower differences in affinity to the four isomers and lower total adsorbed amount. The influence of the different force fields is reflected by a higher ortho-xylene uptake when no partial charges are assigned to the adsorbate pseudo-atoms. The complex role of charge distribution needs further studies, since an inversion between meta-xylene and ethylbenzene selectivity is observed depending on the force field. 
Table 5 - Results of equimolar quaternary adsorption of xylene isomers in UiO-66.

\begin{tabular}{|c|c|c|c|c|c|}
\hline \multicolumn{6}{|c|}{ Temperature: $398 \mathrm{~K}$ / Total pressure: $1.0 \mathrm{kPa}$} \\
\hline & \multirow[b]{2}{*}{ Experimental $^{a}$} & \multicolumn{4}{|c|}{ This work } \\
\hline & & TraPPE & OPLS & $\begin{array}{r}\text { Mod- } \\
\text { TraPPE }\end{array}$ & AUA-ND \\
\hline $\mathbf{p X}$ & 1.82 & 0.86 & 0.91 & 0.95 & 0.89 \\
\hline $\mathbf{m X}$ & 2.04 & 1.17 & 0.98 & 1.24 & 1.73 \\
\hline EB & 2.31 & 1.04 & 1.95 & 0.77 & 0.81 \\
\hline $\mathbf{o X}$ & 3.35 & 8.04 & 6.75 & 8.09 & 8.54 \\
\hline q Total & 9.53 & 11.11 & 10.59 & 11.06 & 11.97 \\
\hline \multicolumn{6}{|c|}{ Temperature: 398 K / Total pressure: 10.0 kPa } \\
\hline & Experimental $^{a}$ & TraPPE & OPLS & $\begin{array}{r}\text { Mod- } \\
\text { TraPPE }\end{array}$ & AUA-ND \\
\hline $\mathbf{p X}$ & 1.91 & 0.94 & 1.07 & 1.04 & 1.13 \\
\hline $\mathbf{m X}$ & 3.09 & 1.33 & 1.24 & 1.37 & 1.55 \\
\hline EB & 2.53 & 1.18 & 2.23 & 0.90 & 0.78 \\
\hline $\mathbf{o X}$ & 5.44 & 8.48 & 7.38 & 8.58 & 11.93 \\
\hline q Total & 12.98 & 11.92 & 11.92 & 11.89 & 15.39 \\
\hline
\end{tabular}

${ }^{a}$ Experimental data from Bárcia et al (2011). Loadings in molecules per unit cell.

\section{CONCLUSIONS}

In this work, we report molecular simulation results of single component and multicomponent adsorption of the four xylene isomers in MOF UiO-66 that confirms its ortho-selectivity, also observed by experiments. Altogether UiO-66 presents reverse shape selectivity for the xylene isomers. The ortho-selectivity is due to entropic effects rather than to the heats of adsorption (enthalpic effects). Molecular simulation is applied as a powerful research tool in predicting accurate results of adsorption properties of potential adsorbent candidates for xylene isomers mixtures that are essential for the development of adsorption based separation processes.

\section{ACKNOWLEDGEMENTS}

This work was supported by projects PTDC/EQU/ERQ/104413/2008 and PestProject PEst-C/EQB/LA0020/2013, co-financed by FEDER through COMPETEPrograma Operacional Factores de Competitividade and by FCT - Fundação para a Ciência e a Tecnologia.

\section{REFERENCES}

ABID, H.R.; PHAM, G.H.; ANG, H-M.; TADE, M.O.; WANG, S. “Adsorption of $\mathrm{CH}_{4}$ and $\mathrm{CO}_{2}$ on Zr-metal organic frameworks.” J. Colloid Interface Sci., v. 366, p. 120-124, (2012). 
ALAERTS, L.; KIRSCHHOCK, C.E.A.; MAES, M.; VAN DER VEEN, M.A.; FINSY, V.; DEPLA, A.; MARTENS, J.A.; BARON, G.V.; JACOBS, P.A.; DENAYER, J.E.M.; DE VOS, D.E. "Selective adsorption and separation of xylene isomers and ethylbenzene with the microporous vanadium(IV) terephthalate MIL-47." Angew. Chem.-Intl. Ed., v. 46, p. 4293-4297, (2007).

ALAERTS, L., MAES, M.; JACOBS, P.A.; DENAYER, J.F.M.; DE VOS, D.E. "Activation of the metal-organic framework MIL-47 for selective adsorption of xylenes and other difunctionalized aromatics.” Phys. Chem. Chem. Phys., v. 10, p. 2979-2985, (2008a).

ALAERTS, L., MAES, M.; GIEBELER, L.; JACOBS, P.A.; MARTENS, J.A. ; DENAYER, J.F.M.; KIRSCHHOCK, C.E.A.; DE VOS, D.E. "Selective adsorption and separation of ortho-substituted alkylaromatics with the microporous aluminum terephthalate MIL-53.” J. Am. Chem. Soc., v. 130, p. 14170-14178, (2008b).

BÁRCIA, P.S.; GUIMARÃES, D.; MENDES, P.A.P.; SILVA, J.A.C.; GUILLERM, V.; CHEVREAU, H.; SERRE, C.; RODRIGUES, A.E. "Reverse shape selectivity in the adsorption of hexane and xylene isomers in MOF UiO-66." Microporous and Mesoporous Materials, v. 139, p. 67-73 (2011).

CAVKA, J.H.; JAKOBSEN, S.; OLSBYE, U.; GUILLOU, N.; LAMBERTI, C.; BORDIGA, S.; LILLERUD, K.P. "A New Zirconium Inorganic Building Brick Forming Metal Organic Frameworks with Exceptional Stability.” J. Am. Chem. Soc. V. 130, p. 13850-13851, (2008).

CHANG, N. AND YAN, C-P. "Exploring reverse shape selectivity and molecular sieving effect of metal-organic framework UIO-66 coated capillary column for gas chromatographic separation” J. Chromatogr. A, v. 1257, p. 116- 124 (2012).

FINSY, V.; VERELST, H.; ALAERTS, L.; DE VOS, D.; JACOBS, P. A..; BARON, G. V.; DENAYER, J. F. M. "Pore-Filling-Dependent Selectivity Effects in the Vapor-Phase Separation of Xylene Isomers on the Metal-Organic Framework MIL-47." J. Am. Chem. Soc., v. 130, p. 7110-7118 (2008).

FINSY, V., KIRSCHHOCK, C.E.A.; VEDTS, G.; MAES, M.; ALAERTS, L.; DE VOS, D.E.; BARON, G.V.; DENAYER, J.F.M. "Framework Breathing in the VapourPhase Adsorption and Separation of Xylene Isomers with the Metal-Organic Framework MIL-53.” Chemistry-a European Journal, v. 15, p. 7724-7731, (2009).

FRENKEL, D. AND SMIT. B. Understanding Molecular Simulations: From Algorithms to Applications. $2^{\text {nd }}$. ed.; Academic Press: San Diego, 2002.

JORGENSEN, W.L.; LAIRD, E.R.; NGUYEN, T.B.; TIRADO-RIVES, J. “Monte Carlo Simulations of Pure Liquid Substituted Benzenes with OPLS Potential Functions.” J. Comput. Chem., v. 14, p. 206-215 (1993).

JORGENSEN, W.L.; MADURA, J.D.; SWENSON, C.J. “Optimized Intermolecular Potential Functions for Liquid Hydrocarbons.” J. Am. Chem. Soc., v. 106, p. 6638-6646 (1984). 
MARTIN M.G. AND SIEPMANN, J.I. "Transferable Potentials for Phase Equilibria. 1. United-Atom Description of n-Alkanes.” J. Phys. Chem. B, v. 102, 2569-2577 (1998).p.

MAES, M.; VERMOORTELE, F.; ALAERTS, L.; COUCK, S.; KIRSCHHOCK, C.E.A.; DENAYER, J.F.M.; DE VOS, D.E., "Separation of Styrene and Ethylbenzene on Metal-Organic Frameworks: Analogous Structures with Different Adsorption Mechanisms”. J. Am. Chem. Soc. V. 132, p. 15277-15285, (2010).

MOREIRA, M. A.; SANTOS, J. C.; FERREIRA, A. F. P.; LOUREIRO, J. M.; RAGON, F.; HORCAJADA, P; SHIM, K.-E.; HWANG, Y.-K.; LEE, U. H.; CHANG, J.-S.; SERRE, C.; RODRIGUES, A. E. "Reverse Shape Selectivity in the Liquid-Phase Adsorption of Xylene Isomers in Zirconium Terephthalate MOF UiO-66”.Langmuir. v. 28, p. 5715-5723 (2012).

MORRIS, W.: TAYLOR, R.E. ; DYBOWSKI, C.; YAGHI, O.M. GARCIAGARIBAY, M.A.; "Framework mobility in the metal-organic framework crystal IRMOF-3: Evidence for aromatic ring and amine rotation”. J. Mol. Struct. V. 1004, p. 94-101 (2011).

NIETO-DRAGHI, C.; BONNAUD P.; UNGERER, P. “Anisotropic United Atom Model Including the Electrostatic Interactions of Methylbenzenes. I. Thermodynamic and Structural Properties”. J. Phys. Chem. C, v. 111, p. 15686-15699 (2007).

VALENZANO, L.; CIVALLERI, B.; CHAVAN, S.; BORDIGA, S.; NILSEN, M.H.; JAKOBSEN, S.; LILLERUD, K.P.; LAMBERTI, C. "Disclosing the Complex Structure of UiO-66 Metal Organic Framework: A Synergic Combination of Experiment and Theory.” Chem. Mater., v. 23, p. 1700-1718 (2011).

WICK, C.D.; MARTIN, M.G.; SIEPMANN, J.L. "Transferable Potentials for Phase Equilibria. 4. United-Atom Description of Linear and Branched Alkenes and Alkylbenzenes.” J. Phys. Chem. B. v. 104, p. 8008-8016 (2000).

WICK, C.D.; SIEPMANN, J. I.; KLOTZ, W. L.; SCHURE. M. R. “Temperature effects on the retention of n-alkanes and arenes in helium-squalane gas-liquid chromatography Experiment and molecular simulation”. J. Chromatogr. A, v. 954, p. 181-190 (2002).

WIERSUM, A.D.; SOUBEYRAND-LENOIR, E.; YANG, Q.; MOULIN, B.; GUILLERM, V.; YAHIA, M.B.; BOURRELLY, S.; VIMONT, A.; MILLER, S.; VAGNER, C.; DATURI, M.; CLET, G.; SERRE, C.; MAURIN, G.; LLEWELLYN, P.L. “An Evaluation of UiO-66 for Gas-Based Applications.” Chem. Asian J. v. 6, p. 3270-3280 (2011).

ZHAI, D.; ZHAO, L.; GAO, J.; XU, C. "Effect of temperature on the diffusion mechanism of xylene isomers in a FAU zeolite: a molecular dynamics study”. Phys. Chem. Chem. Phys., v. 14, p. 7296-7303 (2012). 